\title{
Low-grade inflammation in first-episode psychosis is determined by increased waist circumference
}

\section{Keinänen, Jaakko}

\section{8-12}

Keinänen , J , Suvisaari , J , Reinikainen , J , Kieseppä , T , Lindgren , M , Mantyla , T , Rikandi , E , Sundvall , J , Torniainen-Holm , M \& Mantere , O 2018 , ' Low-grade inflammation in first-episode psychosis is determined by increased waist circumference ' , Psychiatry Research, vol. 270 , pp. 547-553 . https://doi.org/10.1016/j.psychres.2018.10.022

http://hdl.handle.net/10138/323870

https://doi.org/10.1016/j.psychres.2018.10.022

publishedVersion

Downloaded from Helda, University of Helsinki institutional repository.

This is an electronic reprint of the original article.

This reprint may differ from the original in pagination and typographic detail.

Please cite the original version. 


\title{
Low-grade inflammation in first-episode psychosis is determined by increased waist circumference
}

\author{
Jaakko Keinänen $^{\mathrm{a}, \mathrm{b}, *}$, Jaana Suvisaari ${ }^{\mathrm{a}}$, Jaakko Reinikainen ${ }^{\mathrm{c}}$, Tuula Kieseppä ${ }^{\mathrm{d}}$, Maija Lindgren ${ }^{\mathrm{a}}$, \\ Teemu Mäntyläa,e, Eva Rikandi ${ }^{\mathrm{a}, \mathrm{e}}$, Jouko Sundvall ${ }^{\mathrm{f}}$, Minna Torniainen-Holm ${ }^{\mathrm{a}}$, Outi Mantere ${ }^{\mathrm{d}, \mathrm{g}, \mathrm{h}}$ \\ ${ }^{a}$ Department of Public Health Solutions, Mental Health Unit, National Institute for Health and Welfare, P.O. Box 30, FIN-00271 Helsinki, Finland \\ ${ }^{\mathrm{b}}$ Faculty of Medicine, Department of Psychiatry, University of Helsinki, P.O. Box 590, FIN-00029 Helsinki, Finland \\ ${ }^{c}$ Department of Public Health Solutions, Public Health Evaluation and Projection Unit, National Institute for Health and Welfare, P.O. Box 30, FIN-00271 Helsinki, \\ Finland \\ d Psychiatry, University of Helsinki and Helsinki University Hospital, P.O. Box 590, FIN-00029 Helsinki, Finland \\ ${ }^{\mathrm{e}}$ Faculty of Medicine, Department of Psychology and Logopedics, University of Helsinki, P.O. Box 63, FIN-00014 Helsinki, Finland \\ ${ }^{\mathrm{f}}$ Department of Public Health Solutions, Genomics and Biomarkers Unit, National Institute for Health and Welfare, P.O. Box 30, FIN-00271 Helsinki, Finland \\ ${ }^{g}$ Department of Psychiatry, McGill University, 1033 Pine Avenue West, QC, H3A 1A1 Montréal, Canada \\ h Bipolar Disorders Clinic, Douglas Mental Health University Institute, 6875 LaSalle Boulevard, QC, H4H 1R3 Montréal, Canada
}

\section{A R T I C L E I N F O}

\section{Keywords:}

Early psychosis

Chronic inflammation

C-reactive protein

Abdominal obesity

Weight gain

Cardiovascular risk

\begin{abstract}
A B S T R A C T
Psychosis is associated with low-grade inflammation as measured by high-sensitivity C-reactive protein (hsCRP), a risk factor for cardiovascular events and mortality in the general population. We investigated the relationship between hs-CRP and anthropometric and metabolic changes in first-episode psychosis (FEP) during the first treatment year. We recruited 95 FEP patients and 62 controls, and measured longitudinal changes in hsCRP, weight, waist circumference, insulin resistance, and lipids. We used linear mixed models to analyze the longitudinal relationship between hs-CRP and clinical, anthropometric and metabolic measures. At baseline, patients with FEP had higher levels of insulin resistance, total and low-density lipoprotein cholesterol, apolipoprotein B, and triglycerides. Baseline weight, waist circumference, hs-CRP, fasting glucose, and high-density lipoprotein cholesterol were similar between patients and controls. Marked increases in anthropometric measures and hs-CRP were observed in FEP during the 12-month follow-up. However, glucose and lipid parameters did not change significantly. In the mixed models, waist circumference and female sex were significant predictors of hs-CRP levels in FEP. Prevention of the early development of abdominal obesity in FEP is crucial, as abdominal obesity is accompanied by chronic low-grade inflammation, which increases further the cardiovascular risk in this vulnerable population.
\end{abstract}

\section{Introduction}

There is evidence of systemic low-grade inflammation, as measured by the inflammatory marker C-reactive protein (CRP), in severe mental disorders, including schizophrenia (Fernandes et al., 2016), bipolar disorder (Dargél et al., 2015), and major depression (Howren et al., 2009; Wium-Andersen et al., 2013). CRP is a pro-inflammatory protein produced by the liver, and adipocytes may also produce CRP in obese individuals (Anty et al., 2006). The production of CRP is stimulated by the cytokine interleukin 6 (Castell et al., 1990), which is also increased in psychiatric disorders, especially during acute episodes (Goldsmith et al., 2016). CRP has a role in the innate immune system where it activates the complement cascade by binding to the surface of microbes or to compounds released from damaged cells (Pepys and Hirschfield, 2003). High-sensitivity CRP (hs-CRP) assays can be used as a marker of chronic low-grade inflammation. CRP is strongly correlated with body mass index (BMI; $r=0.36,95 \% \mathrm{CI}=0.30$ to 0.42 ) and waist circumference ( $r=0.40,95 \% \mathrm{CI}=0.31$ to 0.48 ) in the general population (Choi et al., 2013). An unhealthy lifestyle can also contribute to an increase in low-grade inflammation; pro-inflammatory activation is associated with a lack of exercise (Hamer et al., 2012), irregular sleeping habits (Wright et al., 2015), and cigarette smoking (Gonçalves et al., 2011; Tibuakuu et al., 2017). Low-grade inflammation predicts insulin resistance (Reilly and Saltiel, 2017), an increased risk of

\footnotetext{
* Corresponding author at: Department of Public Health Solutions, Mental Health Unit, National Institute for Health and Welfare, P.O. Box 30, FIN-00271 Helsinki, Finland.

E-mail address: jaakko.keinanen@thl.fi (J. Keinänen).
} 
cardiovascular diseases (Emerging Risk Factors Collaboration et al., 2010), type 2 diabetes, and cancer (Allin and Nordestgaard, 2011; Calle and Fernandez, 2012). Specifically, CRP is a risk marker for cardiovascular events in the general population, as well as for vascular, cancer, and lung disease mortality (Emerging Risk Factors Collaboration et al., 2010). CRP has been suggested as a useful biochemical risk marker of atherosclerotic cardiovascular disease (Akintoye et al., 2017).

Low-grade inflammation is observed in various mental disorders (Pinto et al., 2017). Accumulating risk factors predispose people with psychiatric disorders to a low-grade inflammatory response. For example, abdominal obesity is prevalent in schizophrenia, bipolar disorder, and major depression (de Wit et al., 2010; Manu et al., 2015; McElroy and Keck, 2012; Saarni et al., 2009). Additionally, people affected by severe mental illness are, on average, physically less active (Stubbs et al., 2016) and smoke more (Dickerson et al., 2017) than the general population. Antipsychotic medication has a strong propensity to cause weight gain and disturb glucose and lipid metabolism (Bak et al., 2014; Newcomer, 2005; Tek et al., 2016). Weight gain in firstepisode psychosis (FEP) is usually rapid during the first weeks and months of antipsychotic treatment (Keinänen et al., 2015; Perez-Iglesias et al., 2014; Tek et al., 2016). Fat accumulation associated with antipsychotic use especially concentrates in the abdomen, resulting in the metabolically most unfavorable form of obesity (Gonçalves et al., 2015). Altogether, these findings suggest a potential role for hs-CRP as an early marker of a process leading to a robust increase in the metabolic and cardiovascular morbidity, as well as mortality, in severe mental illness. This was recently supported by a register-based study where hs-CRP was associated with increased all-cause mortality in people with schizophrenia during a 12-year study period (Horsdal et al., 2017).

The aim of this study was to evaluate how low-grade inflammation, measured by hs-CRP, develops during the first year in FEP. In addition, we investigated longitudinal changes in BMI, waist circumference, glucose, insulin, and lipids. We evaluated the longitudinal effects of risk factors-such as weight gain, abdominal fat, insulin resistance, medication, and smoking-in the development of inflammation. We hypothesized that an hs-CRP rise would be connected to increasing waist circumference and weight, reflecting the pro-inflammatory activation caused by visceral fat accumulation. Furthermore, we hypothesized that the effect of antipsychotics on hs-CRP would be due to increased waist circumference.

\section{Methods}

\subsection{Clinical study protocol and assessment}

The Helsinki Early Psychosis Study recruited FEP patients (aged 18 to 40 years old) attaining their first treatment for psychosis in the catchment area of the Helsinki University Hospital and Helsinki Psychiatric Services in the time period from December 2010 to June 2016. The inclusion criteria for the study were receiving a score of at least 4 for unusual thought content or hallucinations on the Brief Psychiatric Rating Scale - Expanded (BPRS-E) (Ventura et al., 1993) and fluency in the Finnish language. The diagnoses of psychotic disorders according to the DSM-IV criteria were later verified using the Structured Diagnostic Interview for DSM-IV, Research version (First et al., 2002) as well as a review of all medical records. Substance-induced psychotic disorders and psychotic disorders due to a general medical condition were excluded. Patients with FEP were assessed three times. Baseline assessment was conducted as soon as the patient had entered treatment and was able to give informed consent according to the treating personnel. Follow-ups were conducted at two and 12 months. Data were gathered on sociodemographic factors, functioning, medication, physical illness, substance use, physical activity, diet, and smoking; the interviewer measured weight, height, blood pressure, and waist circumference. A full description of the assessment methods and variables is given in the section Supplementary Methods.

Controls-matched by age, sex, and region of residence-were identified from the Population Register Center and assessed at baseline and 12 months with the same protocol as the patients. The exclusion criteria for the controls were a lifetime history of psychotic disorder; chronic neurological, endocrinological, or cardiovascular diseases; and any condition that prevents magnetic resonance imaging.

The study was carried out in accordance with the International Code of Medical Ethics of the World Medical Association (the Declaration of Helsinki). The study protocol was approved by the Ethics Committee of the Hospital District of Helsinki and Uusimaa and by the institutional review boards of the National Institute for Health and Welfare (THL), Helsinki, Finland, and the University of Helsinki. All participants gave a written informed consent.

\subsection{Laboratory analytical methods}

A fasting blood sample was collected at some time between 8 and 10 am. Serum and plasma samples were immediately aliquoted and stored at $-80{ }^{\circ} \mathrm{C}$. Serum total cholesterol, high-density lipoprotein (HDL) cholesterol, triglycerides, hs-CRP, insulin, apolipoprotein A-I (ApoA-I) and apolipoprotein $B(A p o B)$, and plasma glucose were measured on an Abbott Architect ci8200 analyzer (Abbott Laboratories, Abbott Park, IL, USA) in the laboratory of the Genomics and Biomarkers Unit at the National Institute for Health and Welfare. The laboratory has been accredited by the Finnish Accreditation Service and it fulfills the requirements of the standards SFS-EN ISO/IEC 17025:2005. The scope of accreditation covers all analyses. The following methods were used: enzymatic assays for measuring total cholesterol, triglycerides, and glucose; the homogenous method for direct measurement of HDL cholesterol; ultrasensitive immunoturbidimetric assays for ApoA-I, ApoB, and hs-CRP; and a chemiluminescent microparticle immunoassay (CMIA) for insulin. Low-density lipoprotein (LDL) cholesterol was calculated by the Friedewald formula. The mean inter-assay coefficients of variation (CVs) for total cholesterol, HDL cholesterol, triglycerides, hsCRP, insulin, ApoA-I, ApoB, and glucose were 1.0\%, 1.1\%, 0.8\%, 2.8\%, $1.9 \%, 1.2 \%, 1.7 \%$, and $1.1 \%$, respectively.

\subsection{Statistical analysis of clinical data}

Because most of the variables were not normally distributed, we calculated descriptive statistics for sociodemographic and clinical measures using tests for non-normally distributed variables. Thus, we used Pearson's $\chi^{2}$ tests (Fisher's exact test) or the Mann-Whitney $U$-test to test significance in between-group comparisons, and we used Spearman's rank order correlations to test correlations. Friedman's ANOVA was used to test differences between baseline, and two-month and 12-month assessments for patients who had measurements available at all time points. Cochran's $Q$ test was used for categorical variables. For descriptive purposes, we present all $p$-values significant at the $<0.05$ level. The $p$-values for post-hoc pairwise tests conducted after Friedman's ANOVA and Cochran's $Q$ test were Bonferroni corrected.

The statistical comparisons were run on SPSS version 24. We performed mixed effects models using SAS's PROC MIXED to analyze which variables associated with longitudinal changes in hs-CRP in patients. Based on evaluation of model residuals, we applied a logarithm transformation to hs-CRP to reduce the skewness of its distribution (referred to as $\log$ CRP). The selection of model variables was based on the Bayesian information criterion (BIC) (Schwarz, 1978). As there were marked changes in waist circumference and weight over the study period, we analyzed these variables as time dependent. Baseline smoking status was used in the analysis because few patients either started or quitted smoking during the study period, and the amount of missing data on smoking was smallest at baseline. Other variables 
Table 1

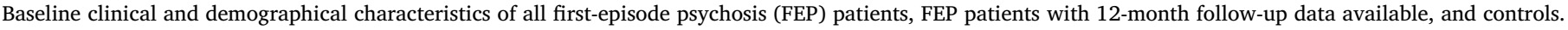

\begin{tabular}{|c|c|c|c|c|}
\hline & $\begin{array}{l}\text { FEP patients }(n=95), n(\%) \\
\text { or median }(25 \%, 75 \%)\end{array}$ & $\begin{array}{l}\text { FEP patients with 12-month follow-up data (CRP) } \\
\text { available }(N=52), n(\%) \text {, or median }(25 \%, 75 \%)\end{array}$ & $\begin{array}{l}\text { Controls }(n=62), n(\%) \text {, } \\
\text { or median }(25 \%, 75 \%)\end{array}$ & $p$-value $^{\mathrm{a}}$ \\
\hline Age & $24.9(21.6,29.4)$ & $25.4(22.6,30.1)$ & $24.0(21.7,28.7)$ & 0.828 \\
\hline Male & $65 / 95(68 \%)$ & $31 / 52(60 \%)$ & $40 / 62(65 \%)$ & 0.611 \\
\hline Living with parents & $35 / 95(37 \%)$ & $18 / 52(35 \%)$ & $10 / 62(16 \%)$ & 0.005 \\
\hline No vocational or higher education & $38 / 95(40 \%)$ & $15 / 52(29 \%)$ & $11 / 62(18 \%)$ & 0.003 \\
\hline Employed, military or student & $73 / 95(77 \%)$ & $41 / 52(79 \%)$ & $59 / 62(95 \%)$ & 0.002 \\
\hline BMI & $22.9(21.1,25.9)(n=94)$ & $23.0(20.9,25.8)(n=83)$ & $23.8(21.8,25.8)$ & 0.356 \\
\hline Waist circumference (cm; total) & $83.0(78.0,90.0)$ & $82.5(75.5,89.0)$ & $82.0(77.0,90.0)$ & 0.519 \\
\hline Waist circumference (cm; men) & $85.0(81.0,91.0)$ & $84.0(79.0,89.0)$ & $86.0(78.0,92.0)$ & 0.443 \\
\hline Waist circumference (cm; women) & $78.5(69.8,86.3)$ & $79.0(71.0,84.5)$ & $79.0(72.8,85.8)$ & 0.584 \\
\hline Smoking & $20 / 78(26 \%)$ & $9 / 47(19 \%)$ & $11 / 53(21 \%)$ & 0.518 \\
\hline No illicit substance use lifetime ${ }^{\mathrm{b}}$ & $40 / 74(54 \%)$ & $27 / 45(60 \%)$ & $26 / 51(51 \%)$ & 0.735 \\
\hline Active lifestyle $^{c}$ & $50 / 72(69 \%)$ & $33 / 44(75 \%)$ & $39 / 51(77 \%)$ & 0.391 \\
\hline Consumption of highly palatable foods ${ }^{\mathrm{d}}$ & $4.5(0-9)(n=70)$ & $4.5(0-9)(n=44)$ & $4(1-9)(n=51)$ & 0.932 \\
\hline Positive symptom score & $6(3,9)$ & $6.5(3,9)$ & $0(0,0)$ & 0.001 \\
\hline Negative symptom score ${ }^{f}$ & $5(3,8)$ & $5(3,8)$ & $0(0,0)$ & 0.001 \\
\hline AUDIT & $5(2,12)(n=74)$ & $4(1,12)(n=45)$ & $6(3,9)$ & 0.797 \\
\hline GAF & $35(31,40)$ & $35(30,40)$ & $86(77,90)$ & 0.001 \\
\hline
\end{tabular}

Abbreviations: AUDIT, Alcohol use disorder identification test; BMI, Body mass index; GAF, Global assessment of functioning scale

a Mann-Whitney $U$ test for continuous variables; chi-squared test for categorical variables.

b Substance use does not include alcohol, nicotine or caffeine.

c Easy exercise at least $4 \mathrm{~h}$ per week, self-reported.

d Sum score of the frequency of consumption of high-energy foods and drinks rich in fat and/or sugar (pizza, hamburgers, chocolate and sweets, cookies, pastries, juices and beverages containing sugar).

e Sum score of BPRS-E items 10 (hallucinations), 11 (unusual thought content), 12 (bizarre behavior) and 15 (conceptual disorganization).

f Sum score of BPRS-E item 16 (blunted affect) and SANS-score (alogia, avolition-apathy, anhedonia-asociality).

considered as potentially associated with hs-CRP were insulin, the homeostatic model assessment (HOMA) index (a measure of insulin resistance), clozapine and olanzapine use, and cannabis use.

\section{Results}

\subsection{Descriptors of the cohort at baseline}

Altogether 95 patients and 62 controls took part in the study at baseline. Baseline serum samples were available for 84 patients and 51 controls. Serum samples at the two-month follow-up were available for 67 patients ( $80 \%$ of the initial sample) and at the 12-month follow-up for 52 patients ( $62 \%$ of the initial sample). Plasma samples for glucose measurement were available for one additional patient in each measurement. The Supplementary Table 1 shows the data available at all three assessments. Patients had a median (Mdn) of 22 days (interquartile range [IQR]: 10-49 days) of antipsychotic use at baseline.

The baseline demographic and clinical characteristics of patients and controls are shown in Table 1. At baseline, there were no significant differences between patients and controls in the lifestyle descriptors, but patients were more often unemployed and living with their parents.

Schizophrenia was the most common diagnosis by the time of the 12-month follow-up ( $n=35,37 \%)$ followed by schizophreniform disorder $(n=22,23 \%)$, psychotic disorder not otherwise specified ( $n=19,20 \%)$, bipolar disorder with psychotic features $(n=8,8 \%)$, major depressive disorder with psychotic features $(n=4,4 \%)$, schizoaffective disorder $(n=3,4 \%)$, brief psychotic disorder $(n=3,3 \%)$ and delusional disorder $(n=1,1 \%)$.

Seven percent of patients $(n=7)$ were not using antipsychotics at the time of baseline assessment. Of patients using any antipsychotic medication at baseline $(n=88), 78(89 \%)$ were prescribed antipsychotic monotherapy. Olanzapine was the most commonly prescribed antipsychotic at baseline $(n=35,37 \%)$, followed by risperidone ( $n=34,36 \%)$, quetiapine $(n=18,19 \%)$ and other second-generation antipsychotics (aripiprazole, sertindole, ziprasidone) $(n=8,8 \%)$. Four percent of patients $(n=4)$ were using first-generation antipsychotics at baseline. Of patients, $60 \%(n=57)$ were hospitalized at baseline. Two patients had insulin treatment for diabetes mellitus at baseline, one for type 1 diabetes and another for type 2 diabetes.

At baseline, patients had higher insulin, insulin resistance (indicated by their HOMA score), total cholesterol, LDL-cholesterol, apolipoprotein $\mathrm{B}$, and triglyceride levels than controls, while hs-CRP at baseline was similar (Table 2). In order to see whether antipsychotic use before the baseline assessment had affected the metabolic parameters at baseline, we divided patients into two groups according to the duration of antipsychotic use before the baseline assessment, using the median (22 days) as a cut-off. There were no statistically significant differences between the two groups in baseline BMI, waist circumference, lipids, glucose or hs-CRP.

\subsection{Medication throughout the study period}

Of those using olanzapine at baseline $(n=35), 71 \%(20 / 28 ; 7$ missing) were still using olanzapine at the two-month follow-up and $48 \%$ (10/21; 14 missing) at the 12-month follow-up.

The proportion of patients not using any antipsychotic at baseline,

Table 2

Baseline laboratory results of first-episode psychosis patients and controls.

\begin{tabular}{llllll}
\hline Variable & Measure & $\begin{array}{l}\text { Patients }(n=84) \\
\text { Median }\end{array}$ & $\begin{array}{l}\text { Controls }(n=51) \\
\text { Median }\end{array}$ & $U^{\mathrm{a}}$ & $p$ \\
\hline hs-CRP & $\mathrm{mg} / \mathrm{l}$ & 0.67 & 0.68 & 2111.5 & 0.890 \\
Glucose & $\mathrm{mmol} / \mathrm{l}$ & $4.11(n=85)$ & 4.06 & 2065.0 & 0.645 \\
Insulin & $\mathrm{mU} / \mathrm{l}$ & 8.85 & 7.40 & $\mathbf{1 6 3 1 . 5}$ & $\mathbf{0 . 0 2 1}$ \\
HOMA & & 1.60 & 1.31 & $\mathbf{1 6 1 6 . 0}$ & $\mathbf{0 . 0 1 7}$ \\
Cholesterol & $\mathrm{mmol} / \mathrm{l}$ & 4.81 & 4.41 & $\mathbf{1 6 9 5 . 0}$ & $\mathbf{0 . 0 4 2}$ \\
HDL-C & $\mathrm{mmol} / 1$ & 1.37 & 1.44 & 2513.5 & 0.092 \\
LDL-C & $\mathrm{mmol} / 1$ & 2.83 & 2.45 & $\mathbf{1 6 1 2 . 5}$ & $\mathbf{0 . 0 1 6}$ \\
Triglycerides & $\mathrm{mmol} / 1$ & 1.11 & 0.83 & $\mathbf{1 4 8 2 . 0}$ & $\mathbf{0 . 0 0 3}$ \\
ApoA-I & $\mathrm{g} / \mathrm{l}$ & 1.44 & 1.45 & 2471.5 & 0.135 \\
ApoB & $\mathrm{g} / \mathrm{l}$ & 0.84 & 0.73 & $\mathbf{1 5 8 1 . 5}$ & $\mathbf{0 . 0 1 1}$ \\
\hline
\end{tabular}

Abbreviations: ApoA-I, apolipoprotein A1; ApoB, apolipoprotein B; HDL-C, high-density lipoprotein cholesterol; HOMA, homeostatic model assessment of insulin resistance; hs-CRP, high sensitivity C-reactive protein; LDL-C, lowdensity lipoprotein cholesterol.

a Mann-Whitney $U$ test. 
Table 3

Baseline, 2-month and 12-month laboratory values, waist circumference and body mass index of first-episode psychosis patients.

\begin{tabular}{|c|c|c|c|c|c|c|c|c|c|}
\hline Variable & Measure & $\begin{array}{l}\text { Baseline } \\
(n=84) \\
\text { Median }\end{array}$ & $\begin{array}{l}25 \% \\
75 \%\end{array}$ & $\begin{array}{l}2 \text { months } \\
(n=67) \\
\text { Median }\end{array}$ & $\begin{array}{l}25 \% \\
75 \%\end{array}$ & $\begin{array}{l}12 \text { months } \\
(n=52) \\
\text { Median }\end{array}$ & $\begin{array}{l}25 \% \\
75 \%\end{array}$ & $\chi^{2 \mathrm{a}}$ & $p^{\mathrm{b}}$ \\
\hline hs-CRP & $\mathrm{mg} / \mathrm{l}$ & 0.67 & $0.33,2.54$ & 0.79 & $0.39,1.92$ & 1.73 & $0.49,4.21$ & 6.731 & $\begin{array}{l}\text { 0.035; BL-2 m 1.000; BL-12 m 0.066; 2m- } \\
12 \mathrm{~m} 0.087\end{array}$ \\
\hline Glucose & $\mathrm{mmol} / 1$ & $4.11(n=85)$ & $3.75,4.50$ & $4.11(n=68)$ & $3.90,4.49$ & $4.23(n=53)$ & $3.95,4.60$ & 2.426 & 0.297 \\
\hline Insulin & $\mathrm{mU} / \mathrm{l}$ & 8.85 & $\begin{array}{l}6.38 \\
14.98\end{array}$ & 8.60 & $\begin{array}{l}6.40 \\
13.10\end{array}$ & 8.40 & $\begin{array}{l}6.10 \\
15.80\end{array}$ & 1.063 & 0.588 \\
\hline HOMA & & 1.60 & $1.14,2.75$ & 1.59 & $1.15,2.62$ & 1.62 & $1.10,2.98$ & 1.636 & 0.441 \\
\hline Cholesterol & $\mathrm{mmol} / 1$ & 4.81 & $4.30,5.37$ & 4.96 & $4.31,5.58$ & 4.87 & $4.26,5.36$ & 0.354 & 0.838 \\
\hline HDL-C & $\mathrm{mmol} / 1$ & 1.37 & $1.15,1.56$ & 1.33 & $1.16,1.56$ & 1.31 & $1.11,1.63$ & 0.149 & 0.928 \\
\hline LDL-C & $\mathrm{mmol} / \mathrm{l}$ & 2.83 & $2.40,3.38$ & 3.02 & $2.45,3.61$ & 2.94 & $2.39,3.39$ & 0.966 & 0.617 \\
\hline Triglycerides & $\mathrm{mmol} / 1$ & 1.11 & $0.75,1.47$ & 1.04 & $0.81,1.47$ & 1.03 & $0.66,1.61$ & 0.184 & 0.912 \\
\hline ApoA-I & $\mathrm{g} / \mathrm{l}$ & 1.44 & $1.27,1.55$ & 1.42 & $1.26,1.53$ & 1.42 & $1.26,1.56$ & 0.667 & 0.717 \\
\hline ApoB & $\mathrm{g} / 1$ & 0.84 & $0.73,0.94$ & 0.86 & $0.75,1.00$ & 0.86 & $0.72,1.04$ & 0.184 & 0.912 \\
\hline Waist circumference & $\mathrm{cm}$ & $83.0(n=95)$ & $78.0,90.0$ & $87.5(n=77)$ & $80.0,99.5$ & $89.0(n=59)$ & $\begin{array}{l}82.0 \\
100.0\end{array}$ & 43.936 & $\begin{array}{l}<0.001 ; \text { BL- } 2 \mathrm{~m}<0.001 ; \text { BL- } \\
12 \mathrm{~m}<0.001 ; 2 \mathrm{~m}-12 \mathrm{~m} 0.249\end{array}$ \\
\hline BMI & $\mathrm{kg} / \mathrm{m}^{2}$ & $22.9(n=94)$ & $21.1,25.9$ & $24.2(n=75)$ & $21.5,26.5$ & $26.3(n=59)$ & $22.8,30.5$ & 44.545 & $\begin{array}{l}<0.001 ; \text { BL-2 m 0.003; BL-12 } \mathrm{m}<0.001 ; \\
2 \mathrm{~m}-12 \mathrm{~m} 0.003\end{array}$ \\
\hline
\end{tabular}

a Friedman's ANOVA.

b $P$-values for pairwise comparison are Bonferroni corrected; Abbreviations: ApoA-I, apolipoprotein A1; ApoB, apolipoprotein B; BL, baseline; 2 m, 2-month follow-

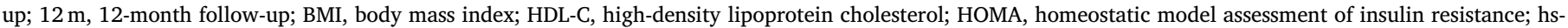
CRP, high sensitivity C-reactive protein; LDL-C, low-density lipoprotein cholesterol.

or the two-month and 12-month follow-ups were $7 \%(7 / 95)$, and $8 \%$ (6/77) and $22 \%(14 / 63)$, respectively. The Supplementary Table 2 shows the distribution of psychotropic medication use at each assessment.

\subsection{Metabolic measures and weight gain in patients at two and 12 months}

As the dates for the two- and 12-month follow-up assessments were agreed upon in cooperation with the patients, there were differences in the actual time between assessments. The median intervals from baseline to the two-month follow-up and from baseline to the 12-month follow-up were 80 days (IQR 69-97 days) and 382 days (IQR 373-397 days), respectively. The median duration of antipsychotic use until the 12-month assessment was 402 days (IQR 374-453). Compared to baseline, waist circumference and BMI had already significantly increased at the time of the two-month follow-up, and continued to increase until the 12-month measurement (Table 3). There were no significant changes in glucose or insulin levels, blood lipids or apolipoproteins between the baseline and the follow-up measurements.

The median 12-month weight gain among FEP patients was $9.6 \mathrm{~kg}$ (IQR $1.4-13.6 \mathrm{~kg}$ ), and the waist circumference increase was $6.0 \mathrm{~cm}$ (IQR $2.0-13.0 \mathrm{~cm}$ ). Compared to patients, controls had statistically significantly less weight gain (Mdn $1.15 \mathrm{~kg}$, IQR $-1.14-2.29 \mathrm{~kg}$, $\mathrm{U}=559.5, p<0.001)$ and increase in waist circumference $(2.0 \mathrm{~cm}$, IQR $-1.38-5.38 \mathrm{~cm}, \mathrm{U}=658.0, p<0.001$ ) by the 12 -month followup. By 12 months, 68\% (40/59) of patients had clinically significant weight gain ( $\geq 7 \%$ weight gain) as compared to baseline and 59\% (35/ $59)$ were overweight or obese. Fourteen percent of patients $(8 / 59)$ had lost weight by 12 months (range of weight loss: $0.2-3.5 \mathrm{~kg}$ ). Of antipsychotics, olanzapine as baseline medication was associated with the greatest 12-month weight increase. Patients using olanzapine at baseline had a median 12-month weight increase of $11.8 \mathrm{~kg}$ (IQR $1.2-18.7 \mathrm{~kg}$ ), while patients not using olanzapine at baseline had a weight increase of $7.6 \mathrm{~kg}$ (IQR 1.5-12.5 kg, $\mathrm{U}=498.0, p=0.056$ ).

In comparison to FEP patients using antipsychotic medication at 12 months $(n=42)$, those who were not using antipsychotic medication $(n=10)$ had less weight increase (respective median weight changes: $10.8 \mathrm{~kg}$, IQR $4.0-14.4 \mathrm{~kg}$ compared to $5.6 \mathrm{~kg}$, IQR - $1.7-10.0 \mathrm{~kg}$; $U=201.5, p=0.043$ ) and waist circumference increase (Mdn $1.0 \mathrm{~cm}$, IQR - 1.0-7.0 cm compared to Mdn $8.5 \mathrm{~cm}$, IQR $4.0-15.3 \mathrm{~cm}$;
$U=160.5, p=0.011)$

The proportion of patients who had elevated waist circumference ( $>94 \mathrm{~cm}$ for men, $>80 \mathrm{~cm}$ for women) at baseline was $27 \%(26 / 95)$, and the proportion increased to $44 \%(34 / 77)$ by the two-month followup and to $54 \%(32 / 59)$ by the 12-month follow-up (Cochran's Q test $\chi^{2}=21.444, p<0.001$ ) (Supplementary Table 3). Apart from waist circumference increase, the prevalence of other metabolic syndrome criteria did not increase significantly over time from baseline to 12 month follow-up, although there was a trend for a higher prevalence of metabolic syndrome at 12 months (Supplementary Table 3).

\subsection{Gender differences in metabolic measures}

Secondary analysis was done to explore gender differences. At baseline, a statistically nonsignificant difference between the proportion of women and men meeting the International Diabetes Federation criteria for increased waist circumference ( $>80 \mathrm{~cm}$ in women, $>94 \mathrm{~cm}$ in men) was detected $\left(40 \%\right.$ and $22 \%$ respectively; $\chi^{2}=3.519$, $p=0.061$ ). Baseline BMI was similar between women and men (Mdn $22.4 \mathrm{~kg} / \mathrm{m}^{2}$, IQR $20.7-25.5 \mathrm{~kg} / \mathrm{m}^{2}$ compared to Mdn $22.9 \mathrm{~kg} / \mathrm{m}^{2}$, IQR $21.2-26.1 \mathrm{~kg} / \mathrm{m}^{2}$, respectively). At 12 months, no statistically significant differences were detected in weight increase $(12 \%$ and $14 \%$ respective increase from baseline weight in women and men) nor in waist circumference increase (7\% and 12\% increase from baseline). There were no statistically significant differences in hs-CRP levels between women and men at any assessment point.

\subsection{Hs-CRP increase and its predictors}

The level of hs-CRP increased significantly in patients from the baseline to the 12-month follow-up (Table 3). Patients who were not using antipsychotics by the 12-month assessment had a trend for lower 12-month hs-CRP (Mdn 0.60, IQR 0.32-1.98 mg/l) than those using antipsychotics (Mdn $2.24 \mathrm{mg} / \mathrm{l}$, IQR $0.56-4.71 \mathrm{mg} / \mathrm{l} ; \quad U=127.5$, $p=0.055$ ). Among controls, hs-CRP was $0.71 \mathrm{mg} / 1$ at the 12 -month follow-up, which was statistically significantly lower than among patients $(\mathrm{U}=565.5, p=0.014)$.

Since we wanted to focus the analysis on low-grade inflammation and exclude patients who probably had an acute infection, we excluded hs-CRP values higher than $10 \mathrm{mg} / \mathrm{l}$ from the mixed effects models. The 
respective number of patients having hs-CRP $>10 \mathrm{mg} / \mathrm{l}$ at baseline, and two-month and 12-month measurements was three, and one and five.

The best-fitting model for longitudinal changes in hs-CRP included a random intercept for each patient and sex, time of assessment (days from baseline measurement), waist circumference and antipsychotic use at each assessment point, and baseline cigarette smoking. Waist circumference $(\beta=0.05048$, standard error $[S E]=0.006646$, $p<0.0001)$ and female sex $(\beta=-0.4721, \mathrm{SE}=0.1882, p=0.0140)$ were statistically significant predictors of higher $\log C R P$. Other variables in this model did not reach statistical significance but based on the BIC they contributed to the model fit. Other tested variables were not significantly associated with $\log \mathrm{CRP}$ and did not improve the model fit, and therefore were not included in the final model. To further explore whether insulin resistance was a significant predictor of logCRP, we included insulin resistance in the model (defined as HOMA above the 75th percentile as in Keinänen et al. (2015), cut-off 2.75), but this did not change results as waist circumference $(p<0.0001)$ and female sex $(p=0.0149)$ were still the only significant predictors. Excluding a patient with diabetes mellitus, who had CRP levels below $10 \mathrm{mg} / \mathrm{l}$, slightly lowered the p-value of female sex $(p=0.0216)$ but otherwise did not change the results of the model.

Replacing waist circumference with BMI decreased the model's goodness of fit slightly, but BMI was also a significant predictor of $\log \mathrm{CRP}(\beta=0.1163, \mathrm{SE}=0.01737, p<0.0001)$.

\section{Discussion}

We detected a remarkable increase in weight and waist circumference in this sample of FEP patients during the 12-month followup. The changes in weight and waist circumference were predictors of low-grade inflammation, as measured by hs-CRP. The observed increase in abdominal obesity is rapid and of great clinical significance in young, originally physically healthy adults.

We found no difference in hs-CRP at baseline between FEP patients and controls. However, hs-CRP increased significantly during the 12 month follow-up among FEP patients, and an increase in waist circumference, reflecting accumulating abdominal fat, was a strong predictor of hs-CRP increase. Waist circumference was a better predictor of hs-CRP than BMI, which fits with findings from the general population (Choi et al., 2013). In the general population, the accumulation of fat in the liver and adipose tissue leads to an increase in hs-CRP, and in addition to the liver's production of CRP, adipose tissue is also a likely source of CRP in obesity (Anty et al., 2006; Zimmermann et al., 2011). The more than 2.5-fold increase in hs-CRP observed in our sample over a one-year period is alarming, taking into account that elevated hs-CRP is associated with an increased risk of cardiovascular disease (Akintoye et al., 2017), and vascular and non-vascular mortality (Emerging Risk Factors Collaboration et al., 2010). While only one study has previously directly associated hs-CRP with prospective mortality in people with severe mental disorders (Horsdal et al., 2017), the robust increase in mortality of these disorders is well established (Nordentoft et al., 2013; Walker et al., 2015). Female sex was also a significant predictor of a higher hs-CRP level and women had a trend for higher hs-CRP level at 12 months. This is in line with findings from the general population that with increasing body fat and BMI, the CRP increases more in women than in men (Choi et al., 2013; Khera et al., 2009).

The FEP patients not using antipsychotics at the time of the 12month follow-up had a trend for lower hs-CRP compared to antipsychotic users, which is probably explained by the smaller increase in waist circumference in non-medicated patients. On average, antipsychotics increase the expression of anti-inflammatory cytokines and decrease the expression of pro-inflammatory cytokines (Fonseka et al., 2016; Tourjman et al., 2013). However, the evidence is equivocal, as in some studies the reverse-or no discernible effect—is detected during antipsychotic use (Baumeister et al., 2016). Our results suggest that weight gain and abdominal obesity are strong drivers of low-grade inflammation and override the potential anti-inflammatory effects that antipsychotics may have.

We observed disturbances in glucose metabolism (i.e. insulin level and insulin resistance) between patients and controls already at baseline. However, there was no worsening of glucose homeostasis during the follow-up. Recent meta-analyses show evidence of impaired glucose tolerance and higher insulin resistance in antipsychotic-naïve FEP patients (Perry et al., 2016; Pillinger et al., 2017a). This could result from an impairment of the hypothalamic-pituitary-adrenal axis function, as FEP has been associated with hypercortisolemia and a blunted cortisol awakening response (Borges et al., 2013). Antipsychotics, especially olanzapine and clozapine, exacerbate elevated glucose levels and increase insulin resistance (Henderson et al., 2006; Newcomer et al., 2002). In our sample, only a minority of FEP patients were antipsychotic-naïve. It is thus possible that use of antipsychotics affected the baseline differences in the present study. Lipid metabolism was dysregulated at baseline in FEP as indicated by higher total cholesterol, triglyceride, and LDL cholesterol and its structural component ApoB levels. These observed differences in lipids could also reflect medication effects. In particular, second-generation antipsychotic use is associated with an increased risk of hyperlipidemia (Meyer and Koro, 2004). Invitro studies show that at first antipsychotics have a direct inhibitory effect on enzymes controlling cholesterol biosynthesis (Canfran-Duque et al., 2013; Kristiana et al., 2010), but a feedback mechanism then increases the lipid synthesis in a matter of hours (Canfran-Duque et al., 2013). It is of interest that, according to meta-analyses, drug-naïve FEP patients may have lower total cholesterol, LDL and HDL cholesterol levels and higher triglyceride levels than healthy controls (Misiak et al., 2017; Pillinger et al., 2017b).

Previous literature has reported an association between high hs-CRP levels and having schizophrenia (Fernandes et al., 2016; Inoshita et al., 2016; Miller et al., 2014; Wang et al., 2017). Our findings are not in total agreement with the results of the meta-analyses, as we did not detect a baseline difference in hs-CRP but detected a significant increase during the first treatment year, which was strongly related to an increase in waist circumference. The largest meta-analysis (Fernandes et al., 2016) including 26 studies found that CRP was increased in both first-episode and chronic schizophrenia. The CRP levels were associated with positive symptom severity and BMI but were not affected by antipsychotic medication or progression of the disease from first-episode to chronic. In a sub-group analysis where only studies with BMI and age-adjusted controls were included, the CRP levels still remained higher in schizophrenia (Fernandes et al., 2016). Mendelian randomization studies analyzing the connection between genetic variants affecting the CRP levels and schizophrenia risk have yielded contradictory results (Hartwig et al., 2017; Inoshita et al., 2016; Prins et al., 2016; Wium-Andersen et al., 2014). A recent study concluded that genetically determined higher CRP levels were associated with a decreased risk of schizophrenia (Hartwig et al., 2017). The authors speculated that higher CRP might provide protection for early-life infections and thus lower the risk of schizophrenia. We conclude that future studies would benefit from using more homogenous groups in terms of the type and duration of medication used as the controversial findings might partially be explained by these factors.

The strengths of this study include a high-quality analysis of hs-CRP in an internationally accredited laboratory. The results can be generalized to FEP patients during the first year of treatment. The controls were randomly recruited from the general population and matched by age, sex, and region of residence, reducing lifestyle-related sociodemographic bias. Mixed model regression analysis allowed us to take into account the individual differences in follow-up times, and allows dependence between repeated observations. We used a prospective follow-up of clinical information that was sampled utilizing many sources, including medical records. 
The limitations of our study include the rather small sample size at the time of the 12-month assessment due to loss at follow-up (62\% had a blood sample available at 12-months). We did not detect any major selection bias due to drop-out and do not expect that to affect our main findings. Most patients were already using antipsychotic medication at baseline. However, the short course of antipsychotic treatment did not result in baseline differences in BMI and waist circumference, nor in hsCRP levels between patients and controls, and thus, did not limit our analysis of the development of increased adiposity and low-grade inflammation. Another limitation is that physical activity was measured with a single, self-report question that does not assess physical activity according to the current recommendations (Bennie et al., 2017; Vancampfort et al., 2016).

Hs-CRP was chosen as the main outcome measure because it can be measured clinically as a marker of cardiovascular risk. However, our results should not be interpreted as suggesting that all immunological abnormalities related to psychotic disorders are caused by weight gain or abdominal obesity. CRP is an acute phase protein produced by liver and to some extent by adipose tissue, not a specific biomarker of immune response. Many previous studies suggest that there are changes, e.g., in T-cell activation, i.e. adaptive immunity, in recent onset psychosis (Drexhage et al., 2011). Our results strengthen the view that regular monitoring of the waist circumference should be an integral part of follow-up of patients. In addition, the potential utility of hs-CRP as a cardiovascular risk marker in patients with psychotic disorder should be studied further.

In conclusion, we describe how a systemic low-grade inflammation is tightly linked with abdominal fat accumulation in FEP during the first year of treatment. Specifically, the low-grade inflammation as measured by hs-CRP was related to an increase in waist circumference and female sex. Clinically, regular follow-up of waist circumference is important as a marker of metabolic and inflammatory changes and as a robust marker of cardiovascular risk. Prevention of the early metabolic changes in FEP is critical in reducing the risk of physical morbidity and mortality in severe mental illness.

\section{Acknowledgments}

We thank Tuula Mononen, Sanna Järvinen and Laura Hietapakka for data collection, and Marjut Grainger for data management. We thank all study participants and clinics.

\section{Funding}

This work was supported by Academy of Finland (\#278171 to JS), the Sigrid Juselius Foundation (JS), the Finnish Cultural Foundation grant (TM and JS), by the Helsinki University Central Hospital (Reference Numbers: TYH2013332, TYH2014228 to OM) and the University of Helsinki (OM and JK).

\section{Conflict of interest}

Jaakko Keinänen owns shares in pharmaceutical company Orion. Tuula Kieseppä has received lecture fees from Lundbeck, Otsuka and Janssen-Cilag. Maija Lindgren has received financial compensation for an interview from Lundbeck. The remaining authors declare no potential conflicts of interests.

\section{Supplementary materials}

Supplementary material associated with this article can be found, in the online version, at doi:10.1016/j.psychres.2018.10.022.

\section{References}

Akintoye, E., Briasoulis, A., Afonso, L., 2017. Biochemical risk markers and 10-year incidence of atherosclerotic cardiovascular disease: independent predictors, improvement in pooled cohort equation, and risk reclassification. Am. Heart J. 193, 95-103. https://doi.org/10.1016/j.ahj.2017.08.002.

Allin, K.H., Nordestgaard, B.G., 2011. Elevated C-reactive protein in the diagnosis, prognosis, and cause of cancer. Crit. Rev. Clin. Lab. Sci. 48, 155-170. https://doi.org/ 10.3109/10408363.2011.599831.

Anty, R., Bekri, S., Luciani, N., Saint-Paul, M.-C., Dahman, M., Iannelli, A., et al., 2006. The inflammatory C-reactive protein is increased in both liver and adipose tissue in severely obese patients independently from metabolic syndrome, type 2 diabetes, and NASH. Am. J. Gastroenterol 101, 1824-1833. https://doi.org/10.1111/j.1572-0241. 2006.00724.x.

Bak, M., Fransen, A., Janssen, J., Van Os, J., Drukker, M., 2014. Almost all antipsychotics result in weight gain: a meta-analysis. PLoS One 9, e94112. https://doi.org/10.1371/ journal.pone.0094112.

Baumeister, D., Ciufolini, S., Mondelli, V., 2016. Effects of psychotropic drugs on inflammation: consequence or mediator of therapeutic effects in psychiatric treatment? Psychopharmacology (Berl) 233, 1575-1589. https://doi.org/10.1007/s00213-0154044-5.

Bennie, J.A., Pedisic, Z., Suni, J.H., Tokola, K., Husu, P., Biddle, S.J.H., et al., 2017. Selfreported health-enhancing physical activity recommendation adherence among 64,380 Finnish adults. Scand. J. Med. Sci. Sport 27, 1842-1853. https://doi.org/10. $1111 /$ sms. 12863.

Borges, S., Gayer-Anderson, C., Mondelli, V., 2013. A systematic review of the activity of the hypothalamic-pituitary-adrenal axis in first episode psychosis.

Psychoneuroendocrinology 38, 603-611. https://doi.org/10.1016/j.psyneuen.2012. 12.025.

Calle, M.C., Fernandez, M.L., 2012. Inflammation and type 2 diabetes. Diabetes Metab 38, 183-191. https://doi.org/10.1016/j.diabet.2011.11.006.

Canfran-Duque, A., Casado, M.E., Pastor, O., Sanchez-Wandelmer, J., de la Pena, G., Lerma, M., et al., 2013. Atypical antipsychotics alter cholesterol and fatty acid metabolism in vitro. J. Lipid Res. 54, 310-324. https://doi.org/10.1194/jlr.M026948.

Castell, J.V., Gómez-Lechón, M.J., David, M., Fabra, R., Trullenque, R., Heinrich, P.C., 1990. Acute-phase response of human hepatocytes: regulation of acute-phase protein synthesis by interleukin-6. Hepatology 12, 1179-1186. https://doi.org/10.1002/hep. 1840120517.

Choi, J., Joseph, L., Pilote, L., 2013. Obesity and C-reactive protein in various populations: A systematic review and meta-analysis. Obes. Rev. 14, 232-244. https://doi. org/10.1111/obr.12003.

Dargél, A.A., Godin, O., Kapczinski, F., Kupfer, D.J., Leboyer, M., 2015. C-reactive protein alterations in bipolar disorder: a meta-analysis. J. Clin. Psychiatry 76, 142.

de Wit, L., Luppino, F., van Straten, A., Penninx, B., Zitman, F., Cuijpers, P., 2010. Depression and obesity: a meta-analysis of community-based studies. Psychiatry Res 178, 230-235. https://doi.org/10.1016/j.psychres.2009.04.015.

Dickerson, F., Schroeder, J., Katsafanas, E., Khushalani, S., Origoni, A.E., Savage, C., et al., 2017. Cigarette smoking by patients with serious mental illness, 1999-2016: an increasing disparity. Psychiatr. Serv. 69, 147-153. https://doi.org/10.1176/appi.ps. 201700118.

Drexhage, R.C., Hoogenboezem, T.A., Cohen, D., Versnel, M.A., Nolen, W.A., Van Beveren, N.J.M., et al., 2011. An activated set point of T-cell and monocyte inflammatory networks in recent-onset schizophrenia patients involves both pro- and anti-inflammatory forces. Int. J. Neuropsychopharmacol. 14, 746-755. https://doi. org/10.1017/S1461145710001653.

Emerging Risk Factors Collaboration,Kaptoge, S., Di Angelantonio, E., Lowe, G., Pepys, M.B., Thompson, S.G., et al., 2010. C-reactive protein concentration and risk of coronary heart disease, stroke, and mortality: an individual participant meta-analysis. Lancet 375, 132-140. https://doi.org/10.1016/S0140-6736(09)61717-7.

Fernandes, B.S., Steiner, J., Bernstein, H.G., Dodd, S., Pasco, J.A., Dean, O.M., et al., 2016. C-reactive protein is increased in schizophrenia but is not altered by antipsychotics: meta-analysis and implications. Mol. Psychiatry 21, 554-564. https://doi. org/10.1038/mp.2015.87.

First, M.B., Spitzer, R.L., Gibbon, M., Williams, J.B.W., 2002. Structured Clinical Interview for DSM-IV-TR Axis I Disorders, Research Version, Patient Edition. (SCID-I/ P). Biometrics Research. New York State Psychiatric Institute, New York, NY.

Fonseka, T.M., Müller, D.J., Kennedy, S.H., 2016. Inflammatory cytokines and antipsychotic-induced weight gain: review and clinical implications. Mol. neuropsychiatry 2, 1-14. https://doi.org/10.1159/000441521.

Goldsmith, D.R., Rapaport, M.H., Miller, B.J., 2016. A meta-analysis of blood cytokine network alterations in psychiatric patients: comparisons between schizophrenia, bipolar disorder and depression. Mol. Psychiatry 21, 1696-1709. https://doi.org/10. 1038/mp.2016.3.

Gonçalves, P., Araújo, J.R., Martel, F., 2015. Antipsychotics-induced metabolic alterations: focus on adipose tissue and molecular mechanisms. Eur. Neuropsychopharmacol. 25, 1-16. https://doi.org/10.1016/j.euroneuro.2014.11. 008.

Gonçalves, R., Coletta, R., Silvério, K., Benevides, L., Casati, M.Z., da Silva, J.S., et al., 2011. Impact of smoking on inflammation: overview of molecular mechanisms. Inflamm. Res. 60, 409-424. https://doi.org/10.1007/s00011-011-0308-7.

Hamer, M., Sabia, S., Batty, G.D., Shipley, M.J., Tabák, A.G., Singh-Manoux, A., et al., 2012. Physical activity and inflammatory markers over 10 years: follow-up in men and women from the Whitehall II cohort study. Circulation 126, 928-933. https:// doi.org/10.1161/CIRCULATIONAHA.112.103879.

Hartwig, F.P., Borges, M.C., Horta, B.L., Bowden, J., Smith, G.D., 2017. Inflammatory biomarkers and risk of schizophrenia: a 2-sample Mendelian randomization study. JAMA Psychiatry 74, 1226-1233. https://doi.org/10.1001/jamapsychiatry.2017. 3191.

Henderson, D.C., Copel, P.M., Borba, C.P., Daley, T.B., Nguyen, D.D., Cagliero, E., et al., 
2006. Glucose metabolism in patients with schizophrenia treated with olanzapine or quetiapine: a frequently sampled intravenous glucose tolerance test and minimal model analysis. J. Clin. Psychiatry 67, 789-797. https://doi.org/10.4088/JCP. v67n0513.

Horsdal, H.T., Köhler-Forsberg, O., Benros, M.E., Gasse, C., 2017. C-reactive protein and white blood cell levels in schizophrenia, bipolar disorders and depression - associations with mortality and psychiatric outcomes: a population-based study. Eur. Psychiatry. https://doi.org/10.1016/j.eurpsy.2017.04.012.

Howren, M.H., Lamkin, D.M., Suls, J., 2009. Associations of depression with C-reactive protein, IL-1, and IL-6: a meta-analysis. Psychosom. Med. 71, 171-186. https://doi. org/10.1097/PSY.0b013e3181907c1b.

Inoshita, M., Numata, S., Tajima, A., Kinoshita, M., Umehara, H., Nakataki, M., et al., 2016. A significant causal association between C-reactive protein levels and schizophrenia. Sci. Rep. 6, 26105. https://doi.org/10.1038/srep26105.

Keinänen, J., Mantere, O., Kieseppä, T., Mäntylä, T., Torniainen, M., Lindgren, M., et al., 2015. Early insulin resistance predicts weight gain and waist circumference increase in first-episode psychosis-A one year follow-up study. Schizophr. Res 169, 458-463. https://doi.org/10.1016/j.schres.2015.11.002.

Khera, A., Vega, G.L., Das, S.R., Ayers, C., McGuire, D.K., Grundy, S.M., et al., 2009. Sex differences in the relationship between C-reactive protein and body fat. J. Clin. Endocrinol. Metab. 94, 3251-3258. https://doi.org/10.1210/jc.2008-2406.

Kristiana, I., Sharpe, L.J., Catts, V.S., Lutze-Mann, L.H., Brown, A.J., 2010. Antipsychotic drugs upregulate lipogenic gene expression by disrupting intracellular trafficking of lipoprotein-derived cholesterol. Pharmacogenomics J 10, 396-407. https://doi.org/ 10.1038/tpj.2009.62.

Manu, P., Dima, L., Shulman, M., Vancampfort, D., De Hert, M., Correll, C.U., 2015. Weight gain and obesity in schizophrenia: epidemiology, pathobiology, and management. Acta Psychiatr. Scand. 132, 97-108. https://doi.org/10.1111/acps.12445.

McElroy, S., Keck, P.J., 2012. Obesity in bipolar disorder: an overview. Curr. Psychiatry Rep. 14, 650-658. https://doi.org/10.1007/s11920-012-0313-8.

Meyer, J.M., Koro, C.E., 2004. The effects of antipsychotic therapy on serum lipids: a comprehensive review. Schizophr. Res. 70, 1-17. https://doi.org/10.1016/j.schres. 2004.01.014.

Miller, B.J., Culpepper, N., Rapaport, M.H., 2014. C-reactive protein levels in schizophrenia. Clin. Schizophr. Relat. Psychoses 7, 223-230. https://doi.org/10.3371/ CSRP.MICU.020813.

Misiak, B., Stańczykiewicz, B., Łaczmański, Ł., Frydecka, D., 2017. Lipid profile disturbances in antipsychotic-naive patients with first-episode non-affective psychosis: A systematic review and meta-analysis. Schizophr. Res. 190, 18-27. https://doi.org/10. 1016/j.schres.2017.03.031.

Newcomer, J., 2005. Second-generation (atypical) antipsychotics and metabolic effects. CNS Drugs 19, 1-93. https://doi.org/10.2165/00023210-200519001-00001.

Newcomer, J.W., Haupt, D.W., Fucetola, R., Melson, A.K., Schweiger, J.A., Cooper, B.P., et al., 2002. Abnormalities in glucose regulation during antipsychotic treatment of schizophrenia. Arch. Gen. Psychiatry 59, 337-345. https://doi.org/10.1001/ archpsyc.59.4.337.

Nordentoft, M., Wahlbeck, K., Hällgren, J., Westman, J., Ösby, U., Alinaghizadeh, H., et al., 2013. Excess mortality, causes of death and life expectancy in 270,770 pat.ients with recent onset of mental disorders in Denmark, Finland and Sweden. PLoS One 8, e55176. https://doi.org/10.1371/journal.pone.0055176.

Pepys, M.B., Hirschfield, G.M., 2003. C-reactive protein: a critical update. J. Clin. Invest. 111, 1805-1812. https://doi.org/10.1172/JCI18921.

Perez-Iglesias, R., Martinez-Garcia, O., Pardo-Garcia, G., Amado, J.A., Garcia-Unzueta, M.T., Tabares-Seisdedos, R., et al., 2014. Course of weight gain and metabolic abnormalities in first treated episode of psychosis: the first year is a critical period for development of cardiovascular risk factors. Int. J. Neuropsychopharmacol. 17, 41-51. https://doi.org/10.1017/S1461145713001053.

Perry, B.I., McIntosh, G., Weich, S., Singh, S., Rees, K., 2016. The association between first-episode psychosis and abnormal glycaemic control: systematic review and metaanalysis. Lancet Psychiatry 3, 1049-1058. https://doi.org/10.1016/S2215-0366(16) 30262-0.

Pillinger, T., Beck, K., Gobjila, C., Donocik, J.G., Jauhar, S., Howes, O.D., 2017a. Impaired glucose homeostasis in first-episode schizophrenia: a systematic review and meta- analysis. JAMA Psychiatry 74, 261-269. https://doi.org/10.1001/jamapsychiatry. 2016.3803.

Pillinger, T., Beck, K., Stubbs, B., Howes, O.D., 2017b. Cholesterol and triglyceride levels in first-episode psychosis: systematic review and meta-analysis. Br. J. Psychiatry 211, 339-349. https://doi.org/10.1192/bjp.bp.117.200907.

Pinto, J.V., Moulin, T.C., Amaral, O.B., 2017. On the transdiagnostic nature of peripheral biomarkers in major psychiatric disorders: A systematic review. Neurosci. Biobehav. Rev. 83, 97-108. https://doi.org/10.1016/j.neubiorev.2017.10.001.

Prins, B.P., Abbasi, A., Wong, A., Vaez, A., Nolte, I., Franceschini, N., et al., 2016. Investigating the causal relationship of C-reactive protein with 32 complex somatic and psychiatric outcomes: a large-scale cross-consortium Mendelian randomization study. PLoS Med 13, e1001976. https://doi.org/10.1371/journal.pmed.1001976.

Reilly, S.M., Saltiel, A.R., 2017. Adapting to obesity with adipose tissue inflammation. Nat. Rev. Endocrinol. 13, 633-643. https://doi.org/10.1038/nrendo.2017.90.

Saarni, S.E., Saarni, S.I., Fogelholm, M., Heliovaara, M., Perala, J., Suvisaari, J., et al., 2009. Body composition in psychotic disorders: a general population survey. Psychol. Med. 39, 801-810. https://doi.org/10.1017/S0033291708004194.

Schwarz, G., 1978. Estimating the dimension of a model. Ann. Stat. 6, 461-464. https:// doi.org/10.1214/aos/1176344136.

Stubbs, B., Williams, J., Gaughran, F., Craig, T., 2016. How sedentary are people with psychosis? A systematic review and meta-analysis. Schizophr. Res. https://doi.org/ 10.1016/j.schres.2016.01.034.

Tek, C., Kucukgoncu, S., Guloksuz, S., Woods, S.W., Srihari, V.H., Annamalai, A., 2016 Antipsychotic-induced weight gain in first-episode psychosis patients: a meta-analysis of differential effects of antipsychotic medications. Early Interv. Psychiatry 10, 193-202. https://doi.org/10.1111/eip.12251.

Tibuakuu, M., Kamimura, D., Kianoush, S., DeFilippis, A.P., Al Rifai, M., Reynolds, L.M., et al., 2017. The association between cigarette smoking and inflammation: The Genetic Epidemiology Network of Arteriopathy (GENOA) study. PLoS One 12, e0184914. https://doi.org/10.1371/journal.pone.0184914.

Tourjman, V., Kouassi, É., Koué, M.-È., Rocchetti, M., Fortin-Fournier, S., Fusar-Poli, P., et al., 2013. Antipsychotics' effects on blood levels of cytokines in schizophrenia: a meta-analysis. Schizophr. Res. 151, 43-47. https://doi.org/10.1016/j.schres.2013. 10.011.

Vancampfort, D., Stubbs, B., Probst, M., De Hert, M., Schuch, F.B., Mugisha, J., et al., 2016. Physical activity as a vital sign in patients with schizophrenia: evidence and clinical recommendations. Schizophr. Res. 170, 336-340. https://doi.org/10.1016/j. schres.2016.01.001.

Ventura, J., Lukoff, D., Nuechterlein, K., Liberman, R., Green, M., Shaner, A., 1993. Brief psychiatric rating scale (BPRS), expanded version (4.0): Scales, anchor points, and administration manual. Int J Methods Psychiatr Res 3, 227-243.

Walker, E.R., McGee, R.E., Druss, B.G., 2015. Mortality in mental disorders and global disease burden implications: a systematic review and meta-analysis. JAMA Psychiatry 72, 334-341. https://doi.org/10.1001/jamapsychiatry.2014.2502.

Wang, Z., Li, P., Chi, D., Wu, T., Mei, Z., Cui, G., 2017. Association between C-reactive protein and risk of schizophrenia: an updated meta-analysis. Oncotarget 8 , 75445-75454. https://doi.org/10.18632/oncotarget.17995.

Wium-Andersen, M.K., Ørsted, D.D., Nielsen, S.F., Nordestgaard, B.G., 2013. Elevated C reactive protein levels, psychological distress, and depression in 73131 individuals. JAMA Psychiatry 70, 176-184. https://doi.org/10.1001/2013.jamapsychiatry.102.

Wium-Andersen, M.K., Ørsted, D.D., Nordestgaard, B.G., 2014. Elevated C-reactive protein associated with late-and very-late-onset schizophrenia in the general population: a prospective study. Schizophr. Bull. 40, 1117-1127. https://doi.org/10.1093/ schbul/sbt120.

Wright, K.P.J., Drake, A.L., Frey, D.J., Fleshner, M., Desouza, C.A., Gronfier, C., et al. 2015. Influence of sleep deprivation and circadian misalignment on cortisol, inflammatory markers, and cytokine balance. Brain. Behav. Immun 47, 24-34. https:// doi.org/10.1016/j.bbi.2015.01.004.

Zimmermann, E., Anty, R., Tordjman, J., Verrijken, A., Gual, P., Tran, A., et al., 2011. Creactive protein levels in relation to various features of non-alcoholic fatty liver disease among obese patients. J. Hepatol. 55, 660-665. https://doi.org/10.1016/j jhep.2010.12.017. 